\title{
No More Need for Landfills in Emerging Economies After 2051
}

\author{
Manfred Fehr* \\ Institute of Geography, Federal University, 38400902 Uberlândia MG, Brazil
}

\begin{abstract}
Literature reports from different emerging economies testify to identical raw domestic waste compositions and support extrapolation of management strategies. Based on 2002 World Summit directives and on experiments with source separation in sample communities, this study develops a realistic timeframe of five decades for complete landfill diversion of this waste. The independent progress variables are determined to be initial collection coverage and demographic expansion. The critical stages separating the time intervals are as follows: starting point in 2003 from local analysis, reduction by one half of residences not served by collection until 2015, turning point of complete collection by 2027 , locally dependent diversion threshold of approximately $67 \%$ of domestic waste by 2039 as result of guided source separation and zero landfilling by 2051.
\end{abstract}

Keywords: Emerging economies, household waste, household waste composition in emerging economies, landfills, landfill diversion of domestic waste, landfill diversion targets, landfills in emerging economies, municipal solid waste management, timeframe for complete landfill diversion, zero waste strategy.

\section{INTRODUCTION}

Domestic waste, or household waste, has been treated exhaustively in the scientific literature. A survey shows, however, that this treatment has largely been concerned with tactics such as raw waste composition, recycling technologies, collection practices, reverse logistics schemes and economics of procedure. Governance strategies such as precise targeting for progressive landfill diversion have not been addressed, although they presently are the single most urgent need of municipal administrators. There exists a strategy gap. The perfect knowledge of domestic waste has not yet been transformed into generally acceptable and applicable targets and deadlines to divert it from the landfill. This text provides a pragmatic proposal to close the gap. It adopts the timeframe set forth by the most authoritative source, namely the last World Summit on Sustainable Development, and combines it with experimental results of source separation. The emerging argument states that landfills for domestic waste may be phased out within five decades after that World Summit.

\section{METHODS AND ARGUMENTATION}

The proposal is meant for emerging economies for two reasons. Firstly of course, the author lives, works and experiments in this community. Secondly, this community is quite homogeneous in terms of domestic waste composition such that the extrapolation of strategies and procedures from one place to another is feasible. Table $\mathbf{1}$ testifies to the validity of this optimistic statement. The almost perfect agreement of composition reports originating from randomly selected developing and emerging nations around the globe cannot be coincidence. In fact, the literature on domestic waste analyses in different countries tends to be repetitive.

*Address correspondence to this author at the Institute of Geography, Federal University, 38400902 Uberlândia MG, Brazil; Tel: +55 343239 4505; E-mail: fehrsilva@lycos.com
The reports shown in Table $\mathbf{1}$ are practically identical. This fact allows the inference that domestic waste management faces the same challenges in Brazil and China e.g., and thus can adopt similar strategies. This argument is fundamental to the proposal of the large scale diversion targets aimed at in the present study.

Approximately $72 \%$ of household waste in the emerging countries is biodegradable, and approximately $28 \%$ is biologically inert and consists of plastics, paper, glass, metals and textiles. From the point of view of waste management in general, no further analyses of unsorted domestic waste appear to be justified. The time has come to fill the strategy gap, and the present text contributes its share to doing this.

There is one hidden fallacy in the mentioned reports. They do not reveal the fact that unsorted or raw waste composition cannot be reproduced by source separation in urban residences, and thus is not a management tool. What remains to be done in urban settings of the developing world in order to construct workable waste management schemes? Experiment with source separation to obtain reliable composition data of sorted waste. Study the reverse logistics facilities and resources available in each setting to stimulate their continued and improved contribution to landfill diversion, and last not least, develop management strategies with precise targets and deadlines to engage the municipal administrations over long periods of time. The strategy consideration will be dealt with here.

What are the available timeframe proposals? The precise target of the World Summit on Sustainable Development, the Johannesburg Summit, of 2002 was and still is to reduce by one half the proportions of people excluded from sanitary services within a timeframe of 12 years, from 2003 to 2015 . Sanitation services within the context of the problem considered here reduce to domestic waste collection and disposal, which are usually provided to residences, not to individuals. So the starting diagnosis, the yearly progress 
Table 1. Unsorted Domestic Waste Compositions Reported from Various Emerging Countries, in Percent

\begin{tabular}{|c|c|c|c|c|c|}
\hline & Brazil & Nepal & Nigeria & India & China \\
\hline biodegradable material & 72 & 71 & 72 & 71 & 72 \\
\hline plastics & 11 & 12 & 11 & 9 & 11 \\
\hline paper and cardboard & 7 & 8 & 3 & 9 & 7 \\
\hline glass & 3 & & 4 & 5 & 5 \\
\hline metals & 3 & & 2 & 4 & 1 \\
\hline textiles & 2 & & 5 & 2 & 2 \\
\hline miscellanea & 2 & 9 & 3 & & 2 \\
\hline
\end{tabular}

requirements and the targets all have to be spelled out in terms of the number of residential units. This procedure produces numbers quite different from the population count. From the point of view of a residential unit, the service is considered complete if the trash is taken away regularly. From the point of view of municipal administrations, the problem is not resolved without finding and using an adequate destination for the trash. The fact remains that the Summit directive implied collection service only. Nothing was specified on destination, so the landfills not only maintained their status but kept growing.

This author believes that developing nations need to jump over some of the paradigms established by developed countries in the past only to be abandoned later. Landfills, incinerators, central sorting facilities and voluntary drop-off points are examples. Landfills may at most be considered temporary trouble shooters within a waste management strategy that adopts World Summit timetables in quest for a zero waste situation. Central sorting and distributed drop-off facilities have been experimented with in Brazil, but have not produced a return compatible with the investment and have been progressively abandoned [1].

When working toward a landfill diversion or a zero waste goal, strategy precedes tactics. Consequently, a generally applicable strategy is proposed here for setting landfill diversion targets in any local context that may easily be quantified and measured. The proposal adopts the time scale set fourth by the World Summit directive, i.e. twelve-year intervals.

Admittedly, the argument is built on the similarities in raw waste composition and economic maturity between the cited countries. Although those are the fundamental parameters for dimensioning similar landfill diversion targets, a few other characteristics may play into particular local strategies, such as degree of urbanization and demographic expansion. Brazil can be regarded as a reasonably stable context with an urban population of $87 \%$ and a yearly demographic expansion of $1.134 \%$. No significant changes in waste production and composition are expected in the near future. China's urban population stands at $47 \%$, indicating potential for migration. This is balanced by the modest demographic expansion of $0.493 \%$ per year. The other countries cited in Table 1 exhibit much higher expansion rates: India $1.344 \%$, Nigeria $1.940 \%$ and Nepal $1.60 \%$ per year. The amount of waste produced there will increase together with the population and in addition as a function of migration to the cities because the urban population represents only $30 \%, 50 \%$ and $19 \%$ for India, Nigeria and Nepal, respectively [6].

The fact remains that landfill diversion strategies are dictated by waste composition and economic situation, and not by generation rates. The latter only define the magnitude of necessary reverse logistics facilities, which are driven by source separation as will be demonstrated in the present study; and source separation efforts are functions of waste composition and economic as well as cultural characteristics. Thus, Table $\mathbf{1}$ is the main basis for the development of a landfill diversion strategy in emerging economies.

\section{RESULTS AND DISCUSSION}

As initial target corresponding to the Johannesburg Summit directive and considered compulsory for any municipal administration, the reduction-by-one-half of the proportions of people not served by domestic waste collection is applied. The twelve-year time span determined by the Summit is adopted as a benchmark not open to discussion.

\section{What Should Have Occurred in the First Term of Twelve Years?}

2002. The World Summit emits the directive to halve, by 2015, the proportions of people without access to basic sanitation. In the present argument this reduces to solid waste collection from residences.

2003. The city administration produces its diagnosis of present waste management practice and establishes the basic parameters for planning. This includes the number of residences, their demographic expansion rate and present coverage of waste collection. From that information, the administration defines the targets and the annual effort required to comply with the directive.

2004. The twelve-year clock starts ticking.

2015. At the end of the twelve-year period, results are reported on the success or failure of the effort to satisfy the directive. Given the long running time, failures to comply were not even addressed by the Summit directive.

\section{Prospect for the Second Term of Twelve Years}

In an attempt to predict the directive originating from the next World Summit, most likely to occur in 2012, two options were explored as obvious candidates. In the first 
option, all municipalities are requested to continue after 2015 with the same collection effort as in the first twelveyear period, until reaching a situation of complete collection service. This will occur at a point in time specific to each city. In the second option, a new twelve-year time frame is arbitrarily established for all municipalities to reach the universal target of complete collection service at the latest by 2027. The two options clearly attend to available local management talent. Good managers will follow the first option. The second option is taken here as bottom line for compliance not open to discussion. After having put into place complete collection practices at any point in time up to 2027, progressive municipal administrations will be looking for pragmatic landfill diversion targets. Complete collection service is the turning point on the time scale where the objective moves from taking more to taking less waste to the landfill. The target starts moving backward from $100 \%$ to $0 \%$ tipping in the long run.

\section{The Third Twelve-Year Term: Moving Ahead of World Summits}

Having accepted the World Summit time scale of twelveyear terms in the forward movement, it is reasonable to continue using it in this backward movement. In this context the question arises as to what should be the target for the third term on the road to zero waste that runs from 2028 to 2039, and that World Summits might only address in 2022 or 20 years after Johannesburg. The target proposed here is based on experiment. It sets the threshold for recycling by private initiative, which may differ from one local community to another. The turning point represents a pragmatic change of procedure, namely to move from managing waste to managing people.

Waste composition so far has only been reported in natura, meaning that all the analyses found in the literature refer to raw waste prior to any sorting effort at the source. Although this kind of composition report is scientifically correct, it does not contribute anything to solving the practical problem of diverting the waste from the landfill. It is of no use to the municipal administrator to know e.g. that $9 \%$ of domestic waste is paper, if there is no way to separate this paper from the mixed lot. The author has experimentally established the fact that source separation drives reverse logistics, and not vice versa. Consequently, landfill diversion by reverse logistics operators is limited to the portion of waste separated at the source. Source-sorted waste composition, then, is the all important parameter for constructing workable schemes for collection and recycling. This simple truth is completely absent from the literature reports on domestic waste analyses.

Consequently, the author experimented with human behavior related to waste movement in order to determine a pragmatic and well explained target for the third interval on the time scale. The experimentation provided answers to two fundamental queries of strategy, namely: What is the best achievable waste composition after source separation? How much coaching effort is required to achieve it?

With this type of information, a municipal administration may fix the diversion target and dimension the corresponding effort for this all important third time interval. The unsorted waste composition in developing countries was shown in Table 1. Upon intensive coaching over a period of ten years, the author was able to arrive at what is considered the best possible sorted waste composition in medium size communities, i.e. the composition after source separation by households. It is shown in Table 2. Inevitably, a third component appeared at the deposit area, namely unsorted waste. Here resides the secret of the theory: At this time, unsorted waste composition is not reproducible upon source separation, even after intense coaching. The unsorted fraction amounted to $33 \%$ in the experiments, and had to be collected and tipped. Nevertheless, $67 \%$ of all waste produced in this community was recycled. The raw waste composition reports in Table $\mathbf{1}$ left the impression that source separation can really produce the composition listed, which is not the case as has been shown here.

The argument for setting a pragmatic target for landfill diversion of domestic waste in the twelve years following the turning point is obvious from Table 2 . The result is experimental and therefore may be reproduced in similar and larger communities in the developing world. Logically, every municipal administration may choose to repeat the source separation test in order to arrive at the correct numbers for the local target. In order to keep the argument flexible, the $67 \%$-diversion point identified in Brazil will be referred to generally as the local management threshold that defines the landfill diversion possible by conveniently stimulated private initiatives. Again, given the long time span, this is considered the bottom line for the slowest moving municipalities.

The target for the third term on the world summit time scale can now be spelled out: In the course of twelve years, starting in 2028 , have at least $80 \%$ of the residences practice source separation with results similar to those shown in Table 2, and provide for reverse logistics to absorb all separated biodegradable and inert items. The landfill diversion should reach the local management threshold.

Table 2. Composition of Source Separated Domestic Waste Best Result Achievable After Intensive Coaching of Medium Size Communities

\begin{tabular}{|c|c|}
\hline biodegradable material appropriate for composting & $47 \%$ \\
\hline recyclable material appropriate for reverse logistics & $20 \%$ \\
\hline trash temporarily tipped at landfill or incinerated & $33 \%$ \\
\hline Source: [1].
\end{tabular}

\section{Meeting the Challenge of Zero Waste During the Fourth and Last Interval}

The previous considerations span 36 years of waste collection and diversion and moved ahead of World Summits on Sustainable Development. Although the theory behind the targeting procedure originated from the 2002 Summit and adopted its time scale, the strategy has become independent from international directives. In fact, the relationship has been reversed. The strategy developed here is now available to be taken into account by future Summit delegates.

The last interval on the proposed time scale will run from 2040 to 2051. What does it ask for in terms of desired achievement? In essence, it needs to consolidate the threshold diversion already reached and develop strategies to 
take care of the remaining mixed waste. This last item consists of material that guided source separation was not able to isolate. At this point in time it is not obvious how to determine the best strategy. The procedure is really limited to three or four choices, such as: Return to coaching and keep working on the perfection of source separation in order to move more items from the trash bin into the recycle bin. Consider incineration of really non-recyclable material, with all its inconveniences. Maintain a limited landfill to absorb residual trash items until other solutions can be found. This type of strategic decision will depend on local conditions and administrative possibilities. No universally applicable and acceptable strategy can be indicated here. In any case, twelve years are available to satisfactorily define what is meant by zero waste in a particular city and to establish the strategy to reach the target.

\section{The Strategy in Form of the Target Schedule}

As a summary of this study, the target schedule shown in Table 3 is put forth to represent the basic strategy of approaching a zero waste situation in the municipal context on a time scale of 48 years extrapolated from the 2002 World Summit directives. The four twelve-year terms discussed in the text are shown with their respective targets.

Table 3. General Target Schedule for Reaching the Stage of Zero Waste in Municipalities of Emerging Economies

\begin{tabular}{|c|c|c|}
\hline Year & Target & \% Tipped \\
\hline \hline 2003 & local diagnosis of waste movement & 100 \\
\hline 2015 & $\begin{array}{c}\text { the universe of residences not served with } \\
\text { collection in 2003 has been halved }\end{array}$ & 100 \\
\hline 2027 & all domestic waste is being collected \\
\hline 2039 & $\begin{array}{c}\text { (turning point) } \\
\text { the local management threshold meaning the best } \\
\text { and all source separated waste is recycled }\end{array}$ & $\sim 33 \%$ \\
\hline 2051 & \begin{tabular}{c} 
the locally defined zero waste situation is reached \\
\hline
\end{tabular} & $\sim 0 \%$ \\
\hline
\end{tabular}

\section{CONCLUSIONS}

The strategy gap referring to target plotting for domestic waste recycling has been filled. The 48 -year timeframe for approaching zero waste is realistic because it derives from World Summit directives. This is the first time that a universal and realistic targeting strategy with a pragmatic timeframe applicable in the developing world is being presented. Progressive municipal administrations can now move ahead of future World Summits and establish their own target schedule toward zero waste.

The independent variables for dimensioning the management effort are initial collection coverage and demographic expansion of residential units.

The four 12-year intervals on the path to complete landfill diversion target the following stages: halve the proportion of residences not served by collection, reach complete collection service, reach the local diversion threshold of approximately $67 \%$, attain the situation defined locally as zero waste.

After reaching the turning point of complete collection, the administrative challenge moves from managing waste to managing people.

\section{ACKNOWLEDGEMENTS}

The Brazilian Research Council CNPq supported this research through grant 301120/2007-2-PQ.

\section{REFERENCES}

[1] M. Fehr, M. S. M. V. Castro, M. R. Calçado, Condominium waste management by private initiative : a report of a 10 -year project in Brazil, Waste Management \& Research, vol. 28 no. 4 pp. 309-314, 2010. http://dx.doi.org/10.1177/0734242X09344337

[2] M. B. Dangi, C. R. Pretz, M. A. Krynowicz, KG. Gerow, J.M. Reddy, Municipal solid waste generation in Kathmandu, Nepal, Journal of Environmental Management, vol. 92, no. 1, pp. 240-249, 2011. http://dx. doi. org/10. 1016/j. jenvman. 2010.09. 005

[3] A. B. Nabegu, An analysis of municipal solid waste in Kano Metropolis, Nigeria, Journal of Human Ecology, vol. 31, no. 2, pp. 111-119, 2010. http://www.krepublishers.com/02-Journals/JHE/JH E-31-0-000-10-Web/JHE-31-2-000-10-Abst-PDF/JHE-31-2-111-1 0-2041-Nabegu-A-B/JHE-31-2-111-10-2041-Nabegu-A-B-Tt. pdf

[4] R. Chatterjee, Municipal solid waste management in Kohima City, India, Waste Management, vol. 29, no. 11, pp. 2909-2910, 2009. http://dx.doi.org/10.1016/j.wasman.2009.07.016

[5] X. Y. Qu, Z. S. Li, X. Y. Xie, YM. Sui, L. Yang, Y. Chen, Survey of composition and generation rate of household waste in Beijing, Waste Management, vol. 29 no. 10 pp. 2618-2624, 2009. http://dx. doi. org/10.1016/j.wasman.2009.05.014

[6] The World Fact Book (accessed: 3008 2011). Available from: http://www.cia.gov/library/publications/the-world-factbook/index.html 